\title{
Meeting Mental Health Needs Following a Natural Disaster: Lessons From Hurricane Katrina
}

\author{
Paula A. Madrid \\ Columbia University and The Children's Health Fund
}

\author{
Roy Grant \\ The Children's Health Fund
}

\begin{abstract}
Hurricane Katrina had a devastating impact on hundreds of thousands of Louisiana and Mississippi families. Housing was destroyed, jobs were lost, and family members were separated, sometimes in different states and without communication. Postdisaster stress reactions were common, with vulnerable individuals most affected. Mental health services were not adequate to meet immediate needs, and postdisaster mental health issues often emerge over time. This article describes the mental health needs of dislocated and evacuee children and families and the steps that were taken to develop mental health programs that would be sustainable over time to meet this new level of need.
\end{abstract}

Keywords: Hurricane Katrina, mental health, disaster mental health, trauma, Katrina lessons learned

In the immediate aftermath of disasters, individuals and organizations often feel compelled to help in whatever capacity may be available to them. Such support has a positive impact on victims and their communities in difficult times. Early evaluation of needs, service delivery, and appropriate interventions are essential in reducing or preventing further consequences of the disaster. Disaster victims often feel abandoned or forgotten after the initial waves of support fade and they are expected to return to normalcy.

Hurricane Katrina was a natural disaster of unprecedented scope. After it made landfall in August 2005, according to the U.S. Department of Homeland Security (2005), about 90,000 square miles were affected to the degree that they were declared national disaster areas. Initial estimates of the number of people displaced

Editor's Note. This article was submitted in response to an open call for submissions about psychologists responding to Hurricane Katrina. The collection of 16 articles presents psychologists' professional and personal responses to the extraordinary impact of this disaster. These psychologists describe a variety of roles, actions, involvement, psychological preparation, and reactions involved in the disaster and the months following. These lessons from Katrina can help the psychology profession better prepare to serve the public and its colleagues.-MCR

Paula A. MAdRID received her PsyD from the University of Hartford. She is the director of the Resiliency Program at the National Center for Disaster Preparedness of Columbia University's Mailman School of Public Health. She is also the director of Mental Health Services for Operation Assist, a joint initiative by the Children's Health Fund and the National Center for Disaster Preparedness to assist victims of Hurricanes Katrina and Rita in the Gulf Coast.

RoY GRANT received his MA from Northeastern University. He is director of research for the Children's Health Fund in New York City and a psychotherapist by training with specialization in early childhood and infant development.

Correspondence Concerning This Article should be addressed to Paula A. Madrid, Director, The Resiliency Program, National Center for Disaster Preparedness, Mailman School of Public Health, Columbia University, 722 West 168th Street, New York, NY 10032. E-mail: pam2109@columbia.edu by Katrina run as high as one million, including 372,000 schoolaged children (Hardy, 2005). Students were evacuated and began school in 46 states. Forty thousand Katrina evacuees attended schools in Texas, with about half in Houston (Cook, 2006). It is more difficult to estimate the number of infants and preschoolers who had to evacuate. Young children are even more vulnerable, depending on their developmental level, to suffering ill effects of the massive disruption caused by the hurricane (Hagan, 2005). The way children think about events is different from the way adults experience disasters. Their expressions of fear and attempts to cope differ as well.

The impact of Hurricane Katrina has been especially difficult for residents of the affected communities because of the extent of their lack of resources before the disaster. In Louisiana, for example, poverty rates in affected areas were as high as $30 \%$ of the population. Among the Katrina evacuees in Houston, 59\% had annual incomes below $\$ 20,000$ in 2004 and about a third (32\%) had incomes below $\$ 10,000$. More than half $(54 \%)$ lacked health insurance, and $40 \%$ had a chronic health condition such as diabetes or a disability. Ninety-three percent were African American (Brodie, Weltzien, Altman, Blendon, \& Benson, 2006). This article describes our experiences providing crisis mental health services under the supervision of a licensed psychologist in the Gulf Coast after Hurricane Katrina and our ongoing work to help build mental health infrastructure in some affected areas, and offers some recommendations for more effective mental health service delivery following a disaster.

\section{The View From the Field}

September 2, 2005-Operation Assist was launched by the Children's Health Fund (CHF), a national organization founded in 1987 by Irwin Redlener, MD, and singer Paul Simon that sponsors health care to medically underserved children in 21 rural and urban sites around the United States, and the National Center for Disaster Preparedness (NCDP) at Mailman School of Public Health, Columbia University. Operation Assist is a collaborative effort to organize programs that support the medical, mental health, and 
public health needs in Gulf Coast communities in Louisiana and Mississippi that were devastated by Hurricane Katrina. In order to ameliorate barriers to access to health care in these already medically underserved communities, Operation Assist uses the CHF model of mobile medical units, essentially pediatric clinics on wheels, staffed with physicians, nurses, and mental health and social service professionals (Redlener, 1993). This model brings medical teams to locations where underserved patients are located, creating access to care for those who are unable to travel to a fixed service site. Several mobile units were immediately deployed in the hardest hit areas of Louisiana and Mississippi at the request of state authorities after the necessary credentialing and other clearances from each state department of health were obtained. This is necessary when working out of state to establish professional credentials and accommodate liability issues.

Our initial field experiences were consistent with the findings from a household survey conducted by the NCDP and Operation Assist investigators in February 2006 of families in transitional housing subsidized by the Federal Emergency Management Agency (FEMA). Abramson and Garfield (2006) found that $34 \%$ of children had at least one chronic health condition. Prescription medication was inadequately available and emergency room utilization was high. Nearly half of parents reported that at least one of their children had new emotional or behavioral problems not observed prior to the hurricanes. More than half of the mothers screened positive for anxiety or depression. These findings are consistent with federal surveillance data. Restricted access to health care in the hurricane-affected areas is indicated by the June 2006 finding that only 140 of 617 primary care doctors had returned to New Orleans, as had only 22 of 196 psychiatrists. Orleans Parish became a federally designated Health Professional Shortage Area (Weisler, Barbee, \& Townsend, 2006).

\section{0th-18th Day Post-Katrina}

Two weeks post-Katrina, Operation Assist expanded with the inclusion of a team of experts in disaster emergency medicine, psychological trauma, and school safety to evacuation sites in San Antonio and Houston, Texas. These cities, especially Houston, had absorbed thousands of children and families from the Gulf Coast. We worked with parents to help them establish a sense of safety and routine for their children, which was extraordinarily difficult under the shelter conditions in which they found themselves. We also helped parents achieve some sense of safety and hope for better living conditions in the immediate future while providing support and validation for their immediate concerns about the way that the evacuation had been conducted and inefficiencies and delays in subsequent government relief efforts (Sobel \& Leeson, 2006). On the basis of clinical impressions, we found that for most of the people we encountered in the shelters, having the opportunity to express their feelings and concerns in a supportive and validating environment was sufficient to help alleviate some of the immediate stress they experienced. When indicated, our clinical team conducted psychological assessments to determine whether crisis intervention or referral for more intensive mental health intervention was needed.

Observing and interacting with children in the shelters provided insight into the initial reactions of children in different age groups to the multiple trauma of the disaster, loss of home and familiar environment, multiple separations, and relocation to often abysmal living conditions. Toddlers and young children presented regressive behavior characterized by clinginess and sometimes by difficulty with brief separations and transitions. Many young children were withdrawn, with depressed and anxious affect. Mothers spontaneously commented on the changes in behavior and mood they observed. Children who had been verbal and friendly with strangers were now described as shy and "out of it," and obedient children began to show behavior problems. Consistent with literature on postdisaster stress reactions (Redlener \& Grant, 2002), older children often presented with somatic symptoms, typically headache and stomach ache. Unlike the younger children, they were able to form peer relations in their new surroundings, which they appreciated as a positive aspect of their current experience. Many older children took on a responsible role in the family, worrying about the impact of the disaster on their parents and sharing the overall sense of uncertainty about the future.

An ongoing concern for nearly all parents was managing their own anxiety. They were responding appropriately to forced separation from their family and friends and an ongoing lack of information about whether these people central to their lives before the hurricane had survived without injury and were currently safe. Sometimes privacy restrictions were cited by officials as the reason why parents were not told whether their children were at a specific shelter. Systems that were supposedly in place were not suitable for the environment and conditions in which people were living. It was interesting to find that some individuals who had evacuated to Texas prior to the hurricane reported that they were not allowed to come to the shelters. They reported that access to the shelters was only for those people who were rescued and/or evacuated after the hurricane through FEMA. Many people reported not having access to information and resources available in the shelters. Although most information was available online, few people had access to computers or the Internet. Public service announcements were not useful when most people did not have electricity or battery-powered radios. There is no question that poor communication and messaging strategies contributed to the protracted anxiety and the beginning of a sense of helplessness reported by many families.

In the earliest stages of our deployment, we made necessary contacts at all levels of state government. Our team coordinated our work with state government officials, who facilitated access to agencies such as the Red Cross, the National Center for Missing and Exploited Children, and Internet databases that listed evacuees in shelters throughout the region. We therefore were able to help with these concrete issues. In some cases, we were able to act as liaisons for family members to contact one another. A considerable amount of the immediate stress and anxiety that families were experiencing could have been avoided or limited by having systems in place for families to learn the whereabouts and condition of their loved ones.

Adults with prior mental health problems are known to be at higher risk for disaster-related stress reactions (Foa, Stein, \& McFarlane, 2006). This is true for children and adolescents as well (Stoddard \& Saxe, 2001), especially when risk is associated with loss of resources and an uncontrollable, fear-inducing event such as a disaster (McCloskey \& Walker, 2000). Following Hurricane Katrina, their vulnerability was compounded by the disruption of ongoing treatment relationships and the unavailability of any pre- 
scribed psychotropic medications. In our experience, few resources were available to individuals with chronic conditions who needed medication and other forms of subspecialty care. As a result, a principal presenting complaint at medical visits was the need for medication management of a prior chronic condition.

Evacuees with a history of trauma were especially vulnerable to postdisaster stress reactions, again consistent with the literature (Parslow, Jorm, \& Christensen, 2006). In Biloxi, Mississippi, we worked closely with hurricane evacuees who had immigrated to America from Vietnam during that war. They reported feeling retraumatized by the hurricane and relocation. This was exacerbated by the squalid and unsanitary circumstances in which they lived, surrounded by foul-smelling trash and rubble.

Many mental health providers relocated after the hurricane because their home, hospital, or practice site had been destroyed. As is typical, psychiatrists were especially scarce, and child psychiatrists even more so, in these poor urban and rural communities (Thomas \& Holzer, 2006). We found that mental health services were typically provided by volunteers, including well-motivated psychology students and professionals at the masters-degree level.

The intense need for mental health services was established shortly after the hurricane. An October 2005 Centers for Disease Control and Prevention (CDC) survey found that half of respondents had a possible need for mental health services, and one third clearly needed intervention. One fourth $(26 \%)$ had a family member who needed counseling, whereas only $1.6 \%$ reported that they were getting the help they needed (Weisler et al., 2006).

Our mental health efforts were led by a licensed psychologist who provided direct services, supervised members of the mental health team, and provided training and technical assistance to local office of mental health providers and school officials and staff. Because of the anticipated high level of need among evacuees, the psychologist focused especially on skill building for staff at the various shelters and relocation centers.

We worked with children by establishing rapport and engaging them in age-appropriate play. After a relatively brief time, most children would feel sufficiently safe to begin talking-even children who by maternal report had been nonverbal since the hurricane. We also attended to the needs of parents and caretakers.

$\mathrm{J}$. is a seven-year-old girl who was evacuated from the Superdome in New Orleans after spending 4 days "sitting on my mother's lap and praying that we would all be ok." According to her mother, in spite of her attempts to reassure her that they would be fine, she was unable to sleep for longer than 3 hours per night. J.'s mother P. is a single mom who lived with her 19-year-old son and her own mother. She reported that they were evacuated together but at some point in the midst of the chaos of finding transportation out of the Superdome with her daughter, they "lost each other." J.'s mother had not seen her mother or son since they evacuated 7 days prior to our meeting. At the time of the meeting, P. and J. asked for help finding their relatives. We were able to research some of the databases available to us but could not find this woman's relatives. We gave her tips on how to help her daughter fall asleep. She had mentioned that she would often sing to her daughter at bedtime, and this routine had been lost. We found a stuffed animal for J., and she found it soothing. We then told $\mathrm{J}$. that because she liked the stuffed animal so much, she could hug it, take slow, deep breaths, and sing to it as she fell asleep.

\section{One Month Post-Katrina}

At this point, we began our work on a mobile medical unit equipped for both medical care and psychotherapy. Several sites were established where the unit could be parked on a regular basis, including Keesler Air Force Base in Biloxi. From this base of operations, the mobile unit was driven to sites along the Mississippi Gulf Coast, which were otherwise medically unserved. Patients were seen on a walk-in basis. We encountered many people who met criteria for acute stress disorder, especially among those with prior vulnerability, and many others who presented with varying levels of anxiety, panic attacks, new onset depressive episodes, and substance abuse. We heard reports of youth experiencing more serious symptoms of acute stress, including flashbacks, dissociation, nightmares, difficulty sleeping, poor concentration, crying spells, and feeling subjectively traumatized. The trauma experienced by the individuals we served was so complex that it was important to keep in mind the presence of acute stress disorder, bereavement, grief reactions, and the beginning of posttraumatic stress disorder.

For younger children, we provided brief play therapy interventions following streamlined psychological assessments. When working with children, we always included the parents in the intervention, providing them with support, validation, and psychoeducation. Under the extreme circumstances of the post-Katrina environment, access to the most basic play materials was limited, adding to the stress on young children who not only lost their familiar toys but did not have new ones as substitutes. Where possible, we used day-care facilities as a source of toys and coloring books and as environments in which children could interact with peers under appropriate adult supervision. We worked with shelter staff to help develop as normal and predictable a routine as possible for children and provided support to those children who were able to attend a new school. With their children engaged in an age-appropriate daily routine, parents were free of daytime child-care responsibilities and were able to devote their time to integrating into their new surroundings and looking for work and housing. They were also able to continue their search for information and hoped-for reunions with friends and family members whose whereabouts were still unknown. This also gave parents time to take advantage of the medical and mental health services that we had available.

\section{8th-57th Day Post-Katrina}

By this time we were well-established in Mississippi for mental health work. Although relatively minor medical complaints were common, the presenting problems were most often psychological, ranging from mild stress reactions to significant signs of posttraumatic stress and depression. Symptoms included frequent crying, generalized sadness and/or anxiety, hyperarousal, somatic complaints (chiefly new onset headaches), and sleep difficulties. We worked with children and adults whose prior mental health relationships had been severed. This was a particularly difficult time for parents because Halloween was fast approaching, and they were understandably concerned about whether this would be another source of stress or trauma for their children.

The sheltered evacuees appeared subdued, were superficially friendly but distracted, and reported feeling worried that something 
bad would happen again soon. The evacuation sites were isolated and surrounded by devastation as far as one could see. Homes were damaged or destroyed. People wandered around the rubble picking up any of their former possessions that might be salvageable, although most of it seemed to us to be irreparably destroyed.

Many schools in Mississippi had reopened, and teachers found they had to balance academic work with newly emerging mental health needs, whether for nurturance and support or more specific help with emotional and behavioral problems. The stress on teachers was magnified by their own loss; about $80 \%$ had their homes destroyed in the hurricane. To the extent that they were available, school-based health centers engaged in screening students for symptoms of trauma. It was difficult to refer children for treatment. Community-based mental health resources had been inadequate prior to the hurricane, and many private practices had been destroyed. Psychologists and other mental health professionals had to leave the area and were themselves not yet permanently relocated. Chronically mentally ill patients at residential treatment facilities that had been destroyed were relocated to other states, some as far away as North Dakota. Many of the mental health clinicians who remained were themselves overwhelmed and traumatized.

As is typical when community-based mental health options are severely limited, hospital emergency rooms became the default site for acute treatment (Padgett \& Brodsky, 1992). Overwhelmed by the need, hospital emergency rooms began to divert psychiatric cases, quickly overwhelming the few remaining psychiatrists who were unable to keep up with the demand for psychopharmacology visits.

While doing outreach at local housing projects, we encountered residents who had been clients at mental health clinics that were no longer functional and who were now seeking care at hospital emergency rooms. The most common presenting problems were sleep disturbance, preoccupation with death, and anxiety that severe weather events would cause additional suffering. In this environment, we observed children to be much clingier with their adult caretakers than is typical for children their ages. People at all ages seemed distracted and preoccupied, and their interactions struck us as shallow. We observed people to be irritable and easily agitated, especially when dealing with the rubble and debris that surrounded them.

The mother of a comatose 15-year-old boy in Mississippi who was displaced because of the hurricane met with one of our clinicians. The mother reported that she had been providing care for him for the last 3 months. The boy had been comatose for several years following a diving accident. The mother reported that her son was finally admitted to the hospital to have his feeding tube replaced because of a leak. The mother presented with extreme anxiety and depression and asked for housing assistance until they received their FEMA trailer. Our team worked to help her find housing and assistance for her son and provided supportive interventions.

In our continued work with children and their parents, we encountered many families struggling with behavior management, confusion about how to talk to children about the events they had experienced, and trouble coping with the significant changes they had endured. We worked with parents to help them set limits for their children, but this was extremely difficult in the unstructured if not chaotic environments in which they had been forced to relocate. We screened parents for symptoms of more serious psychopathology in order to offer appropriate interventions. For those who did not need more intensive intervention, we provided support, psychoeducation, validation, and normalization of fears and concerns. An important part of our interventions could be characterized as intensive case management. We provided help with immediate and concrete service needs, making connections with available community agencies and other sources of support such as the Red Cross or other volunteer organizations to help ensure that necessities such as food and clothing were available.

We found it effective to help parents begin to grieve the losses they had experienced and to consider rebuilding their lives as best as they could. Parents needed to feel more in control of their circumstances, as is typical of sheltered families such as the homeless (Meadows-Oliver, 2003). Parents became better able to positively integrate their situation as they accepted change as an inevitable part of life and saw that, despite the adverse circumstances they were experiencing, goals could be established and progress could be made toward achieving them. We found that many parents were very resilient and able to identify sources of strength and support (very often in religious settings). They were beginning to discuss their new realities and thinking about the future. As we were able to help people in their attempts to reestablish community connections such as housing, employment, and health care, the intensity of their feelings of loss and uncertainty diminished (Madrid, Grant, Reilly, \& Redlener, 2006).

\section{3rd-74th Day Post-Katrina}

Over time, the impact of evacuation and relocation emerged to the forefront of the mental health problems we encountered in the shelters and other temporary residences that we visited. Children and their parents were having grief reactions to all they had lost, compounded by uncertainty about the future. The frequent and multiple relocations that evacuee families endured added to their sense that their future was unpredictable, and this undermined the sense of control that we had tried to reestablish. Children did not experience predictable routines, could not form new friendships, or did not experience any other signs of stability that would help mitigate their ongoing sense of confusion. Often they did not even have a consistent caregiver because of protracted family separations. This further compromised their sense of trust and comfort.

The lack of any foreseeable resolution to the extraordinary problems that parents were facing added to a pervasive sense of despair about the future. Adequate housing and jobs were not possible to find because of the slow pace of recovery in the impacted areas. The mental health problems we observed are consistent with literature on refugees and evacuees nationally and internationally and indicate the extreme level of need of these vulnerable children and families as we approach, as of this writing, the 1-year anniversary of Hurricane Katrina (Lustig et al., 2004; Porter \& Haslam, 2005).

In February 2006, 6 months after Hurricane Katrina, we dispatched a team of public health investigators to survey health and mental health needs of evacuee families in FEMA trailer camps in New Orleans. Key findings included the following: One third (34\%) of the children had at least one chronic health condition; nearly half of surveyed parents reported that their child showed new emotional or behavioral problems; $20 \%$ of school-aged chil- 
dren were still out of school; and on average, these evacuee families had relocated three and one half times since the hurricane (Abramson \& Garfield, 2006).

These findings were consistent with those of a September 2005 survey of evacuees in Houston shelters done in the weeks immediately after Katrina (Brodie, Weltzien, Altman, Blendon, \& Benson, 2006). From the degree to which these early signs of mental health need among children and families were evident, with the understanding that the mental health problems of children emerge over time (Davis \& Siegel, 2000), it was clear that the need for expanded mental health services in the Gulf Coast would be ongoing for years to come. And, as was the case in New York City following the terror attacks of 9/11/01, federal disaster relief money for mental health services often had to be used for superficial "crisis counseling" rather than for psychotherapy or other clinical interventions because of the way that key federal agencies, FEMA and the Substance Abuse and Mental Health Services Administration, interpreted the relevant portion of the Stafford Act (Section 416), which is the operative legislation for postdisaster federal aid (Weisler et al., 2006). These restrictions on mental health access combined with compelling survey results soon after the disaster only added to the expectation that the need for psychological services would be both intense and long standing (Voelker, 2005).

\section{Developing Mental Health Programs in the Gulf Coast Following Hurricane Katrina}

In addition to providing direct services to children and families throughout the affected region, we have been continuously working with governments in Louisiana and Mississippi to help strengthen their mental health infrastructure. We began by working with key agencies (health, mental health, education) to develop a plan for ongoing collaboration. The principal mental health issue discussed was the need for hospital emergency room back-up for Gulfport Memorial Hospital. Because there were only 20 psychiatric beds, it was a strain to keep up with the many emergency room users sent there from four smaller hospitals. A consistent problem emerged around fatigue and burnout of community officials and providers (Madrid \& Schacher, 2006).

By this time, it was clear that full-time mental health programs from our Operation Assist initiative were needed. Our mental health director, a clinical psychologist, began a series of biweekly meetings with key state and local mental health officials (including private and community-based mental health providers and agencies, local elementary and high school officials, day treatment centers and community hospital staff) commuting to Mississippi and Louisiana from New York City.

An important part of our work has been the development of our Community Support and Resiliency Programs (CSRP) in Baton Rouge, Louisiana, and Gulfport/Biloxi, Mississippi, as permanent programs in the Gulf Coast. The CSRP staff comprises licensed psychologists, clinical social workers, and professional counselors who conduct their work in community support units. These are mobile units designed for delivery of mental health services and integrated with primary care to the affected communities. Services are available at predetermined sites on a consistent basis and include intake; supportive interventions; and individual, group, and family therapy.
$\mathrm{R}$. is a 42-year-old woman who was trapped by floodwater on the third floor of her sister's New Orleans' house. There were 10 other relatives with her. She reported that they survived by cooking with candles and an aluminum pan in which they were able to fry bacon, eggs, pork chops, and frozen waffles. Eventually they ran of out of water and felt that they would soon die. R. reported that she and her family spent a lot of time by the window making signals to the helicopters they saw, but to no avail. After 5 days a helicopter arrived and airlifted 7 of them- "my mother, her sister, my young brother, three nieces (one pregnant with twins), and a cousin"- to a highway (I-10 in New Orleans East). Two days later, R. and the rest of her family were airlifted and reunited on the highway. R. stated that they slept on the road for 2 days before they were flown on another helicopter to New Orleans' International Airport. They stayed there for 3 days before being taken to San Antonio, Texas. R. recently came back to Louisiana with her family. They are all living in one trailer intended for no more than four people. When we saw her, R. presented with anxiety attacks, trouble sleeping, significant weight loss, nightmares, and anger outbursts. She is seeing one of the therapists in our mobile unit program for assessment and short-term intervention.

As part of our ongoing work to provide mental health support to children, families, and providers, the mental health team developed coping boxes and has been distributing them throughout the fall. Coping boxes are small, plastic boxes that contain toys and materials considered to have potential therapeutic value to children. The idea behind the box is that we all need a "toolbox" of coping skills and resources. This is true for adults and more so for children as they are more likely to benefit from concrete objects that provide them with an opportunity to begin to learn about coping. Having something tangible can often help children, especially during difficult times. The boxes contain stickers, Silly Putty, finger puppets, a Slinky toy, a note pad, a pencil, and other objects. The boxes have been given to children by mental health providers, teachers, and pediatricians who explain to the child what coping means; how important it is for them to store important objects, memories, writings, and so forth, in the box; and how to use the box when feeling stress.

\section{Lessons Learned}

The need and demand for mental health services for survivors along the Gulf Coast will continue for many years to come. Psychologists working with disaster victims and their families have reported a great deal of trauma experienced by those impacted by the hurricane, with widespread generalized grief, anxiety, and fear. Those with a history of past trauma and loss are at greater risk for a reoccurrence of anxiety, problems with sleep and concentration, uncontrolled anger, and other behavioral problems in response to this disaster.

Federal and often local disaster relief policies tend to underemphasize mental health preparedness and interventions relative to physical health. As was often the case in New York City after the terrorist attacks of 9/11/01 and more recently in Louisiana and Mississippi following Hurricane Katrina, insufficient attention is paid to the long-term nature of mental health needs after the traumatic disaster or incident (Redlener \& Grant, 2002). Furthermore, mental health treatment by professionals skilled in psychotherapy, psychopharmacology, or a combination thereof should be 
integrated into disaster relief efforts to help adults and children cope with stress, anxiety, depression, and other behavioral disorders in addition to more chronic mental health problems. Preventing emotional dysfunction or breakdown and restoring individuals to a predisaster level of functioning is essential to community resilience and recovery and future disaster preparedness.

It is essential that city, state, and federal governments as well as the insurance industry adopt short-term and long-term solutions that facilitate accessible care and reimbursement with parity between physical health and mental health services. As we saw following the terrorist attacks of $9 / 11 / 01$, there is an urgent need to increase the number of qualified practitioners through efficient credentialing and incentives for psychologists and other mental health professionals who engage in disaster care and posttrauma interventions. There is also a need for the business community and government to support adequate access to mental health services provided by qualified professionals - whether psychologists, social workers, psychiatrists, or other trained mental health professionals. The value of early posttrauma intervention cannot be overemphasized (Alexander, 2005).

As of this writing, 17 months have passed since Hurricane Katrina hit, leaving chaos, loss, and some level of disruption to the lives of hundreds of thousands of people. Through the efforts of many, those in need have received initial support, interventions, and resources. Communities have done their best to utilize the limited resources available to them. It is our belief that resilience can be fostered in the aftermath of a disaster such as Hurricane Katrina by planning ahead and meeting the ongoing needs of those impacted. Yet, people's safety must first be secured with adequate shelter, food, medications, and clothing in order to begin the process of healing from psychological trauma. Similarly, family reunification is essential to the well-being of children and parents. When their basic needs are met, people have a degree of control, empowerment, and normalcy in their lives, which is vital to recovery. This process of normalization can be fostered through psychoeducational interventions by psychologists and other mental health professionals. First, essential family needs must be met. Next, families should be provided with the social support they need to recognize their own strengths and resources (Cryder, Kilmer, Tedeschi, \& Calhoun, 2006; Howard \& Goelitz, 2004).

Ongoing services will be required to help evacuees adjust to their new community or to their prior community if they are able to return. Many families will continue to need help establishing (or reestablishing) medical and mental health service relationships, and all can be expected to also need assistance with financial obligations to deal with typical daily challenges as they arise. Psychologists and other mental health professionals, as well as pediatricians and other healthcare providers, have the obligation to advocate for their patients' ongoing needs (Hagan, 2005). Even 1 year after a disaster, some say recovery has not yet started.

To meet the needs of children, the child care infrastructureday-care centers, Head Start programs, and schools-must have the level of resources necessary to meet a new and emerging level of need. This includes increased facility capacity and availability of the full range of operational resources. This should also include training and staff support in the identification of and intervention for typical and atypical child reactions to trauma (Gaines \& Leary, 2004).
In order to provide ethical and competent mental health services, one needs to take into account cultural issues impacting helpseeking and accepting behavior as well as the traditional sources of support and well-being that the community relies on. Our experience highlighted the importance of understanding the culture, spirituality, and beliefs of those we served and in the development of long-term or permanent programs (Seidenberg, 2006). We suggest that minority professionals be hired and consulted, and that past discrimination, racism, and restricted access to health care be taken into account as factors that may prevent access to and utilization of health and mental health services that are offered.

A recurrent finding in our work has been the importance of meeting the needs of those who are responsible for children (Appleyard \& Osofsky, 2003). Helping to meet the concrete, employment, and psychological needs of parents, guardians, teachers, and all service professionals whose mission is the well-being of children is crucial in order to expedite individual, family, and eventually community healing and recovery. Children obtain their sense of safety from the cues they perceive from adults, and a predictable routine and consistent support system proves beneficial in periods of anxiety, uncertainty, and stress. It has been our experience that parents often prioritize caring for their children at the expense of their own mental health needs. As such, providing psychoeducation, support, and resources to adults can be invaluable interventions to preserve the integrity of families and thus communities.

Finally, it is critical that mental health considerations become an integral part of disaster preparedness, response, and recovery. This should be especially true for children and others at risk and vulnerable populations. A comprehensive list of preparedness recommendations and guidelines dealing with child mental health concerns and considerations in dealing with the disabled can be found in the reports of national consensus conferences of the National Center for Disaster Preparedness (2003, 2005).

\section{References}

Abramson, D. A., \& Garfield, R. A. (2006). On the edge: Children and families displaced by Hurricanes Katrina and Rita face a looming medical and mental health crisis. Retrieved January 23, 2007, from http://www.ncdp.mailman.columbia.edu/program_special.htm

Alexander, D. A. (2005). Early mental health intervention after disasters. Advances in Psychiatric Treatment, 11, 12-18.

Appleyard, K., \& Osofsky, J. (2003). Parenting after trauma: Supporting parents and caregivers in the treatment of children impacted by violence. Infant Mental Health Journal, 24, 111-125.

Brodie, M., Weltzien, E., Altman, D., Blendon, R. J., \& Benson, J. M. (2006). Experiences of Hurricane Katrina evacuees in Houston shelters: Implications for future planning. American Journal of Public Health, 96, 1402-1408.

Cook, G. (2006). Schooling Katrina's kids. American School Board Journal, 193, 18-26.

Cryder, C. H., Kilmer, R. P., Tedeschi, R. G., \& Calhoun, L. G. (2006). An exploratory study of posttraumatic growth in children following a natural disaster. American Journal of Orthopsychiatry, 76, 65-69.

Davis, L., \& Siegel, L. J. (2000). Posttraumatic stress disorder in children and adolescents: A review and analysis. Clinical Child and Family Psychology Review, 3, 135-154.

Foa, E. B., Stein, D. J., \& McFarlane, A. C. (2006). Symptomatology and psychopathology of mental health problems after disaster. Journal of Clinical Psychiatry, 67, 15-25. 
Gaines, S. K., \& Leary, J. M. (2004). Public health emergency preparedness in the setting of child care. Family and Community Health, 27, $260-265$

Hagan, J. F., \& the Committee on Psychosocial Aspects of Child and Family Health and the Task Force on Terrorism. (2005). Psychosocial implications of disaster or terrorism on children: A guide for the pediatrician. Pediatrics, 116, 787-795.

Hardy, L. (2005). News analysis: After the storm, schools reach out to traumatized students. American School Board Journal, 192, 4-6.

Howard, J. M., \& Goelitz, A. (2004). Psychoeducation as a response to community disaster. Brief Treatment and Crisis Intervention, 4, 1-10.

Lustig, S. L., Kia-Keating, M., Knight, W. G., Geltman, P., Ellis, H., Kinzie, J. D., et al. (2004). Review of child and adolescent refugee mental health. Journal of the American Academy of Child and Adolescent Psychiatry, 43, 24-36.

Madrid, P. A., Grant, R., Reilly, M. J., \& Redlener, M. B. (2006). Challenges in meeting immediate emotional needs: Short-term impact of a major disaster on children's mental health: Building resiliency in the aftermath of Hurricane Katrina. Pediatrics, 117, S448-S453.

Madrid, P. A., \& Schacher, S. (2006). A critical concern: Pediatrician self-care after disasters. Pediatrics, 117, S454-S457.

McCloskey, L. A., \& Walker, M. (2000). Posttraumatic stress in children exposed to family violence and single-event trauma. Journal of the American Academy of Child and Adolescent Psychiatry, 39, 108-115.

Meadows-Oliver, M. (2003). Mothering in public: A meta-synthesis of homeless women with children living in shelters. Journal for Specialists in Pediatric Nursing, 8, 130-136.

National Center for Disaster Preparedness, Mailman School of Public Health, Columbia University. (2003). Pediatric preparedness for disasters and terrorism: A national consensus conference (Executive Summary). Retrieved January 23, 2007, from www.bt.cdc.gov/children/pdf/ working/execsumm03.pdf

National Center for Disaster Preparedness, Mailman School of Public Health, Columbia University. (2005). Considerations in emergency preparedness: A two track conference. (Available by request from http:// www.ncpdp.mailman.columbia.edu).

Padgett, D. K., \& Brodsky, B. (1992). Psychosocial factors influencing non-urgent use of the emergency room: A review of the literature and recommendations for research and improved service delivery. Social Science \& Medicine, 35, 1189-1197.
Parslow, R. A., Jorm, R. A., \& Christensen, H. (2006). Associations of pre-trauma attributes and trauma exposure with screening positive for PTSD: Analysis of a community-based study of 2,085 young adults. Psychological Medicine, 36, 387-395.

Porter, M., \& Haslam, N. (2005). Predisplacement and postdisplacement factors associated with mental health of refugees and internally displaced persons: A meta-analysis. Journal of the American Medical Association, 294, 602-612.

Redlener, I. (1993). Overcoming barriers to health care access for medically underserved children. Journal of Ambulatory Care Management, 16, 21-28.

Redlener, I., \& Grant, R. (2002). The 9/11 terror attacks: Emotional consequences persist for children and their families. Contemporary Pediatrics, 19, 43-59.

Seidenberg, J. (2006). Cultural competence in disaster recovery: Lessons learned from the Hurricane Katrina experience for better serving marginalized communities. Retrieved January 31, 2007, from www.law. berkeley.edu/library/disasters/Seidenberg.pdf

Sobel, R. S., \& Leeson, P. T. (2006). Government's response to Hurricane Katrina: A public choice analysis. Public Choice, 127, 55-73.

Stoddard, F. J., \& Saxe, G. (2001). Ten-year research review of physical injuries. Journal of the American Academy of Child and Adolescent Psychiatry, 40, 1128-1145.

Thomas, C. R., \& Holzer, C. E. (2006). The continuing shortage of child and adolescent psychiatrists. Journal of the American Academy of Child and Adolescent Psychiatry, 45, 1-9.

U.S. Department of Homeland Security. (2005). Hurricane Katrina: What government is doing. Retrieved January 25, 2007, from www.dhs.gov/ interweb/assetlibrary/katrina.htm

Voelker, R. (2005). Katrina's impact on mental health likely to last years. Journal of the American Medical Association, 294, 1599-1600.

Weisler, R. H., Barbee, J. G., \& Townsend, M. H. (2006). Mental health and recovery in the Gulf Coast after Hurricanes Katrina and Rita. Journal of the American Medical Association, 296, 585-588.

Received September 13, 2006

Revision received April 4, 2007 Accepted April 16, 2007 